\title{
Diffusion of Plasticizer in a Solid Propellant Based on Hydroxyl-Terminated Polybutadiene
}

\author{
Juliano Libardi, Sergio P. Ravagnani \\ Faculdade de Engenharia Química, UNICAMP \\ Ana M. F. Morais, Antonio R. Cardoso \\ Instituto de Aeronáutica e Espaço, IAE
}

\begin{abstract}
The aim of this work was to determine the dioctyl azelate (DOZ) plasticizer diffusion coefficient (D) for samples containing the interfaces of rubber, liner and solid composite propellant based on hydroxyl-terminated polybutadiene (HTPB). The samples used in the diffusion study were aged up to 31 days after the cure period at $80^{\circ} \mathrm{C}$. A computer program implementing a mathematical model of Fick's second Law of diffusion was developed to calculate the diffusion coefficient based on concentration data obtained from gas chromatographic analyses. The effects of the diffusion phenomenon were also investigated by Shore A hardness and scanning electron microscope (SEM) techniques. These analyses were carried out using samples aged at room temperature and at $80^{\circ} \mathrm{C}$. The hardness results showed an increasing trend for the samples aged at room temperature; however in the tests carried out at $80{ }^{\circ} \mathrm{C}$ they showed the opposite trend. The SEM analyses detected meaningful changes in the surface morphology of the propellant for both aging temperatures.
\end{abstract}

Keywords: Diffusion, solid propellant, hardness, SEM, plasticizer, HTPB.

\section{Introduction}

The rocket motor is a device comprised of a combustion chamber charged with solid composite propellant. One chamber extremity contains an ignition system and the other, a nozzle, which expels the hot combustion gases. The internal wall of this chamber is coated with a layer of an insulating rubber which protects the vessel against the high temperature of combustion. An adhesive liner is used to tack the propellant to the rubber layer ${ }^{[1]}$.

The composite propellant based on the hydroxyl-terminated polybutadiene binder usually contains about 80 weight percent ammonium perchlorate (AP) and aluminum powder (Al) solids, 15 weight percent hydroxyl-terminated polybutadiene (HTPB) and five weight percent additives, of which the plasticizer represents up to 60 weight percent ${ }^{[1-3]}$.

The polymeric matrix is obtained by the reaction of the hydroxyl-terminated polybutadiene with the isocyanate (NCO) group from the isophorone diisocyanate (IPDI) cure agent. The resulting polyurethane formed binds the ingredients of the propellant and also acts as a fuel. The mechanical properties of the solid propellant are determined by the degree of crosslinking of this matrix, which is controlled by the $\mathrm{NCO} / \mathrm{OH}$ ratio ( $\mathrm{R}$ value $)^{[4-6]}$.

The plasticizer is used as an additive to increase the flexibility, softness and workability of the propellant. This agent is responsible for the reduction in tensile strength and elastic modulus of the material. The addition of plasticizer to the propellant composition provides properties suitable for storage, application and transportation $^{[7]}$.

Otherwise, the mechanical properties of the propellant may undergo degradation due to the diffusion of the plasticizers. Other species as crosslinking agents, burn rate catalysts, cure agent catalysts can also diffuse due to their low molecular weight and because they are not bound to the polymer matrix. This process occurs mainly at the interfaces of the propellant, liner and rubber and can cause separation between the thermal insulation and the propellant ${ }^{[8-11]}$.

The propellant also undergoes a natural process of deterioration defined as aging. This phenomenon affects the mechanical properties such as hardness, elongation at break, maximum stress and others ${ }^{[8-16]}$. The main mechanisms that govern aging are attributed to loss of plasticizer by diffusion and oxidation of the polymeric matrix ${ }^{[1,12]}$. In general, these processes occur at room temperature and can be accelerated by increasing the temperature during the aging period.

In this work a computer program based of Fick's second law of diffusion was developed to calculate the diffusion coefficient of the plasticizer DOZ present in the composition of the solid propellant. The software used the concentration data from chromatographic analyses obtained up to 31 days after the cure period from samples aged at $80{ }^{\circ} \mathrm{C}$.

According to Byrd and Guy ${ }^{[9]}$ the diffusion of various substances can interfere with the propellant cure, producing a soft layer and resulting in a week bond between the interfaces. Therefore, to verify the effect of diffusion on the mechanical property near to the interface propellant/liner/rubber the shore A hardness tests were conducted. The values usually found in the literature at $20{ }^{\circ} \mathrm{C}$ are about 55 shore $\mathrm{A}^{[17]}$.

To conduct these tests the samples were submitted to natural and accelerated aging at $80{ }^{\circ} \mathrm{C}$ for 54 days. This interval was established based on previous studies ${ }^{[18]}$, with samples aged at $50{ }^{\circ} \mathrm{C}$. The hardness tests were performed on different regions of the propellant to confirm the occurrence of softening, and the SEM technique was used to verify changes in the superficial morphology of the propellant during aging period.

\section{Experimental}

\section{Mathematical model}

The phenomenon of diffusion on propellant/liner/insulation rubber layers occurs due to the differences in concentration between these regions. The diffusion system can be described by Fick's second law of diffusion ${ }^{[19]}$, represented by Equations 1 and 2. 


$$
\frac{\partial C}{\partial t}=D \nabla^{2} C
$$

Assuming diffusion in one direction $z$ of a plane sheet:

$$
\frac{\partial C}{\partial t}=D \frac{\partial^{2} C}{\partial z^{2}}
$$

and assuming the region $-l<z<l$ of one plane sample thickness of $2 l$, to have a constant concentration $\left(C_{0}\right)$ at $(t=0)$ and concentration $\left(C_{1}\right)$ on the surface. The following conditions were used:

a) Initial condition:

at $\mathrm{t}=0$ and $\forall-l<\mathrm{z}<l \rightarrow C(l, 0)=C_{0}$

b) Boundary conditions:

at $t>0$ and $z=0 \rightarrow \partial C / \partial z=0$ and at $t>0$ and $z=1 \rightarrow C(l, t)=C_{l}$.

Applying the conditions above and using the method of separation of variables it was obtained the Equation 3:

$$
\frac{M_{t}}{M_{e q}}=1-\sum_{n=0}^{\infty} \frac{8}{(2 n+1) \pi^{2}} \exp \left(-D(2 n+1)^{2} \pi^{2} t / 4 l^{2}\right)
$$

where $M t$ is the mass concentration in the test layer in period $t$, $M e q$ is the mass concentration at equilibrium and $D$ is the diffusion coefficient.

Equation 3 and the least squares and Newton-Raphson methods were used to calculate the diffusion coefficient through the computational program developed for this work.

\section{Sample preparation}

Metallic boxes with internal dimensions $130 \times 130 \times 65 \mathrm{~mm}$ (length $\times$ height $\times$ thickness) were used to prepare the samples. Firstly, the insulation rubber (NBR7113) was placed in the box and then an adhesive liner, called LHNT, was applied to its surface. In the next stage, the box was filled with the propellant forming the interfaces of interest in this work and submitted to the cure process at $50{ }^{\circ} \mathrm{C}$ during seven days. The basic propellant composition contains $84 \%$ solids (aluminum and perchlorate ammonium) immersed in the hydroxyl-terminated polybutadiene resin and $3.2 \% \mathrm{w} / \mathrm{w}$ dioctyl azelate (DOZ) plasticizer. The rubber used is a nitrilic type with dioctyl phthalate (DOP) plasticizer in its composition.

\section{Plasticizer extraction}

Immediately after the end of the cure process, the block of sample containing the layers of propellant/liner/rubber was removed from the metallic box. The sample was sliced into six pieces $10 \mathrm{~mm}$ thick each one and aged at $80^{\circ} \mathrm{C}$ during 31 days. On days $1,3,7,12$, 20 and 31 one slice was removed from the stove and cooled to room temperature. Then both layers of the rubber and liner were separated from the propellant and identified as (PT). The layer containing only the propellant was cut at distances of 5 and $15 \mathrm{~mm}$ from the interfacial layer and identified as (P1) and (P2), respectively.

Each one of the layers, (PT), (P1) and (P2), was fragmented into small square pieces having approximately the dimensions of $5 \times 5 \mathrm{~mm}$. From these pieces $1 \mathrm{~g}$ of the material was separated and transferred to the filter paper. In the next step, this paper was placed into the Soxhlet extractor which was then filled with $150 \mathrm{~mL}$ of ethyl acetate. The process of extraction was carried out at $75^{\circ} \mathrm{C}$ for 16 hours. The whole process was conducted in triplicate with each layer being submitted to ten extractions.

After extraction, the chromatographic analysis was carried out to determine the plasticizer mass concentration.

\section{Gas chromatography}

The chromatographic analyses were performed using a Varian gas chromatography (CG) with an ionization flame detector and a Finningan Mass Spectrometer (MS). The column utilized was a
DB5 (5\% phenyl methyl silicon) with a diameter of $0.25 \mathrm{~mm}$, a porosity of $0.25 \mu \mathrm{m}$ and length of $30 \mathrm{~m}$. To conduct the analyses an $1 \mathrm{~mL} / \mathrm{min}$ nitrogen flow rate was utilized and $1 \mu \mathrm{L}$ of the sample was injected.

\section{Scanning electron microscopy (SEM)}

The samples used in the SEM and Shore A analyses were provided by Divisão de Química (AQI/IAE). The block was divided into two groups of six samples each. One group was aged at $80^{\circ} \mathrm{C}$ and the other was aged at room temperature. On days 20, 27, 40 and 54 after the cure period both groups were submitted to SEM analysis.

This interval was chosen based on previous work ${ }^{[17]}$ where was observed that the diffusion phenomenon reached equilibrium approximately 50 days after the cure. In this work the analyses were conducted on the regions of the propellant adjacent to the interface.

To investigate the propellant surface a LEO 440i scanning electron microscope (SEM) with $\mathrm{Si} / \mathrm{Li}$ (Oxford) detectors was utilized. The surfaces of the samples were metallized using a polaron sputter coater. During the analyses a $10 \mathrm{kV}$ voltage and $100 \mathrm{pA}$ current were applied.

\section{Shore A hardness}

A durometer with a Shore A digital scale was used according to ASTM D 2240 - 05 $5^{[20]}$.

This test measures resistance to penetration by an indentor pressed into the sample under a constant load; the values were obtained after the digital indicator was stabilized.

The indentations were made in three different regions of the propellant referred as R1, R2 and R3, located respectively 3,25 and $55 \mathrm{~mm}$ from the composite interface with the liner. After 20, 27, 40 and 54 days of curing the six samples aged at room temperature and at $80{ }^{\circ} \mathrm{C}$ were submitted to hardness analyses. Five indentations were made in order to obtain consistent results.

\section{Results and Discussion}

\section{Diffusion coefficient}

Figure 1 shows the mass concentration data on the DOZ plasticizer obtained by chromatographic analyses of the samples aged at $80{ }^{\circ} \mathrm{C}$ plotted as a function of time. The (PT) curve represents the mass concentration of the $\mathrm{DOZ}$ in the interface of the rubber and liner and the curves for (P1) and (P2) represent the DOZ concentration of the propellant layer between 0 and $5 \mathrm{~mm}$ and 5 and $15 \mathrm{~mm}$ from the interface, respectively.

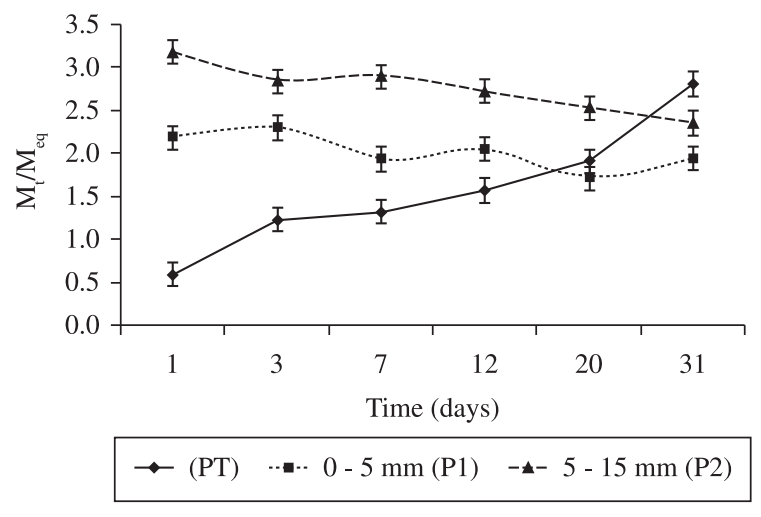

Figure 1. DOZ mass concentration at $80{ }^{\circ} \mathrm{C}$ as a function of time in the layers (PT), (P1) and (P2). 
Figure 1 shows that the plasticizer molecules diffused from the propellant into the insulation or from regions of higher concentrations to regions of lower concentrations. These curves indicate that the diffusion of the DOZ occurred during and after the cure of the propellant. It can also be seen from the curves that due to the proximity to the interface, in the period analyzed, the loss of plasticizer is greater on layer (P2) than on (P1). This difference in concentration gradient is responsible for the largest diffusion coefficient calculated in the P2 as shown in Table 1 . The DOZ diffusion coefficients shown in this table were calculated by a mathematical model of Fick's second law of diffusion.

As show in Table 1, the diffusion coefficient obtained for layer (P2) is higher than that obtained for the layer (P1). However, it was expected that the obtained results for both regions would be similar as the initial composition of the propellant and the concentration of the plasticizer are the same.

Therefore, due to the difference, in concentration between the interface layers, it is possible that other free species as curing agent and burn rate catalysts diffuse from propellant to rubber. Thus, it is possible that unbounded species from thermal insulation also diffuse into the propellant. These processes can affect the polymer network firstly near the interface and can be responsible for the differences

Table 1. DOZ diffusion coefficients obtained on the layer of rubber and liner (PT) and on layers (P1) and (P2) of the propellant at $80^{\circ} \mathrm{C}$.

\begin{tabular}{cc}
\hline Sample layer & Diffusion coefficient $\left(\mathbf{D} \times \mathbf{1 0 7}\left(\mathbf{c m}^{2} \cdot \mathbf{s}^{-1}\right)\right.$ \\
\hline$(\mathrm{PT})$ & 0,70 \\
$(\mathrm{P} 1)$ & 2,29 \\
$(\mathrm{P} 2)$ & 6,27 \\
\hline
\end{tabular}

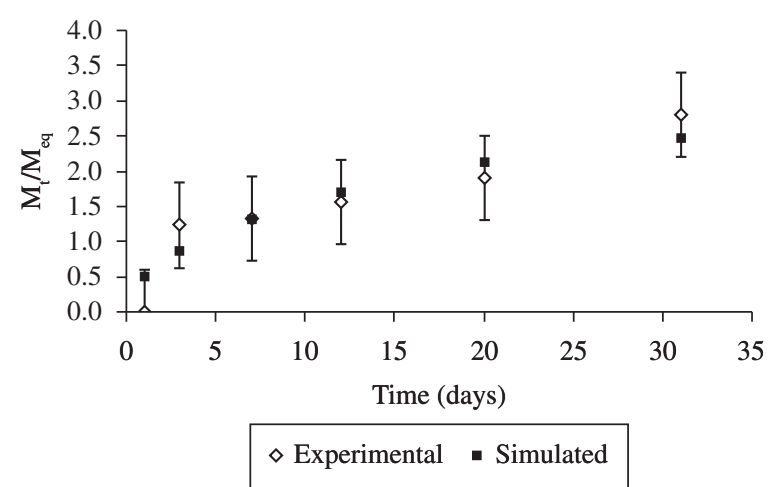

Figure 2. Experimental and simulated diffusion curves for DOZ on layer (PT) at $80{ }^{\circ} \mathrm{C}$.

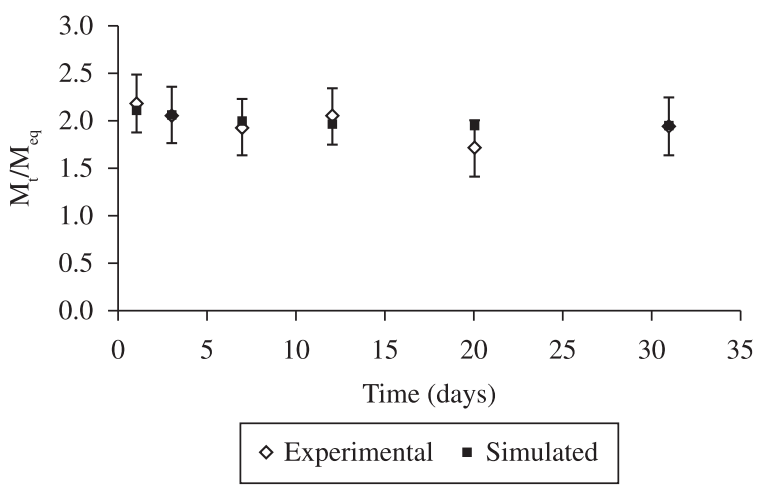

Figure 3. Experimental and simulated diffusion curves for DOZ on layer (P1) at $80^{\circ} \mathrm{C}$ found between the DOZ diffusion coefficients of layers (P1) and (P2).

Figures 2, 3 and 4 display the experimental and simulated diffusion curves for $\mathrm{DOZ}$ aged at $80^{\circ} \mathrm{C}$. In these figures it is possible to verify good agreement between theoretical and experimental curves which validates the model.

\section{SEM analyses}

The micrography in Figure 5 shows the interface region of a sample obtained 20 days after the cure period and aged at room temperature. The aluminum powder $(\mathrm{Al})$ particles tend to reside on the surface where their atoms undergo oxidation and form a typically white compound $\left(\mathrm{Al}_{2} \mathrm{O}_{3}\right)$, as can be seen in the image in Figure 5. In this image the darkest regions represent the polymeric matrix and the other components of the propellant. The holes in the interfaces were created during the slicing of the samples.

Figure 6 shows the SEM micrographies of the samples aged at room temperature (Figure 6a) and at $80{ }^{\circ} \mathrm{C}$ (Figure 6b). These images illustrate the differences in superficial morphology between the samples aged at different temperatures and also the changes in relation to the initial morphology illustrated in Figure 5.

The propellant is highly loaded with the aluminum and ammonium perchlorate solids which are distributed in the elastomeric binder. The micrography (a) in Figure 6 clearly shows these solids structures, which are of different sizes and are predominant in the superficial morphology. However, the morphology observed in Figure $6 \mathrm{~b}$ is quite different, as the solids particles seem to be

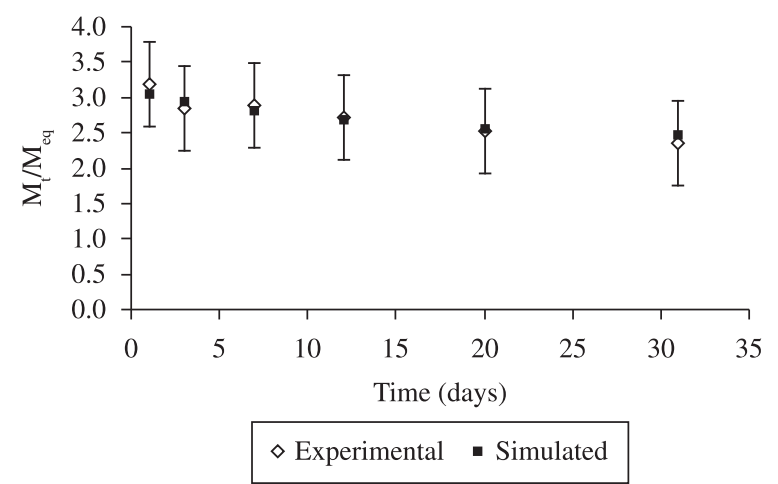

Figure 4. Experimental and simulated diffusion curves for DOZ on layer (P2) at $80^{\circ} \mathrm{C}$.

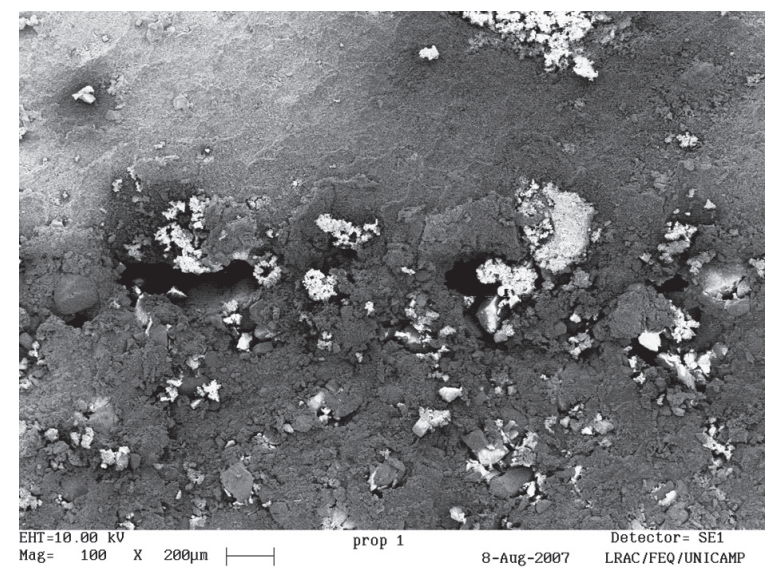

Figure 5. SEM micrographie $(100 x)$ of the interfacial layer between propellant and liner obtained 20 days after the cure period at room temperature. 


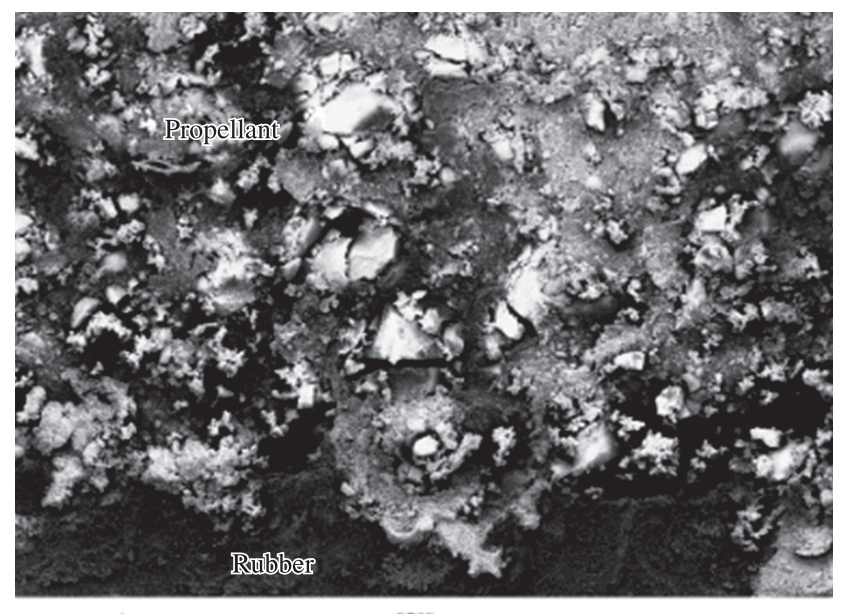

166u | HO8 $160 \mathrm{x}$ prop

(a)

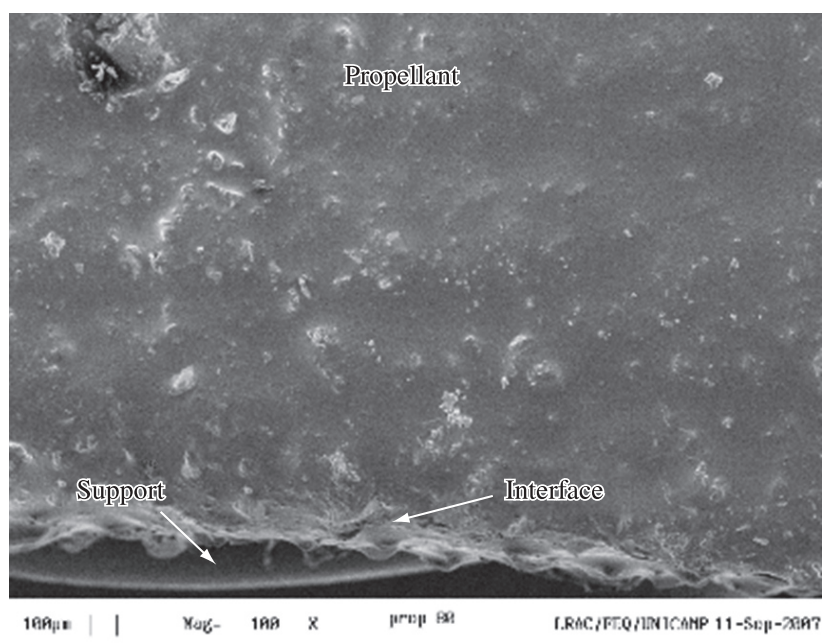

(b)

Figure 6. SEM micrographies $(100 \times)$ of the interval layer of the propellant sample obtained 54 days after the end of the cure period, aged at: a) room temperature; and b) $80^{\circ} \mathrm{C}$.

embedded in the matrix. The origin of these changes is probably attributed to the elevated temperature and the increase of the diffusion process of the plasticizers, which can cause modifications in the structure of the polymer network and also in the interaction between the solids particles and the matrix.

Furthermore, due to the high hygroscopic potential of the ammonium perchlorate, the ambient moisture could be incorporated into the propellant structure during and after its fabrication, as the samples were not submitted to relative humidity. The higher temperature during aging might have activated a process of water desorption. This phenomenon can also affect the structure of the composite propellant and consequently its morphology and mechanical properties.

\section{Shore A hardness}

Figure 7 shows hardness as a function of time for samples aged at room temperature. The indentations were made in propellant regions R1, R2 and R3 located respectively 3, 25 and $55 \mathrm{~mm}$ from the interfacial layer.

The curves in Figure 7 show an increasing trend of hardness with aging time. The values obtained in regions $\mathrm{R} 2$ and $\mathrm{R} 3$ are similar and higher than the values found in region $\mathrm{R} 1$. These results indicate a softening in the first $3 \mathrm{~mm}$ of the propellant. The same phenomenon was observed in samples aged at $80{ }^{\circ} \mathrm{C}$ (Figure 8), where lower values of hardness were also found in the region nearest to the interface. Due to the proximity to the interface, it is possible that the plasticizer "dragged" the curing agent (NCO) from the composite to the rubber layer during the cure period. Thus, the loss of this agent affected the $\mathrm{NCO} / \mathrm{OH}$ ratio, reducing the crosslink density of the matrix and consequently its hardness near the interface.

The diffusion of plasticizer can explain the hardening of the propellant with aging at room temperature. However, the oxidation of the polymeric matrix can also explain this behavior. In this case, more specific analyses should be conducted to confirm this hypothesis.

The results of the hardness tests given in Figures 7 and 8 illustrate the different aging behavior of the propellant at room temperature and at $80^{\circ} \mathrm{C}$. As observed in Figure 8 the effect of temperature aging caused degradation of the hardness with aging time.

The diffusion of the plasticizer and "loss" of the curing agent during the cure period can not explain the decrease in hardness

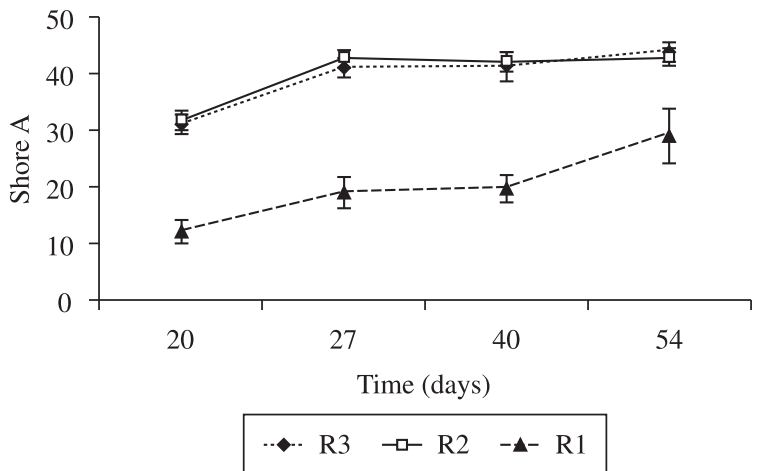

Figure 7. Shore A hardness as a function of time for propellant regions R1, $\mathrm{R} 2$ and $\mathrm{R} 3$ aged at room temperature.

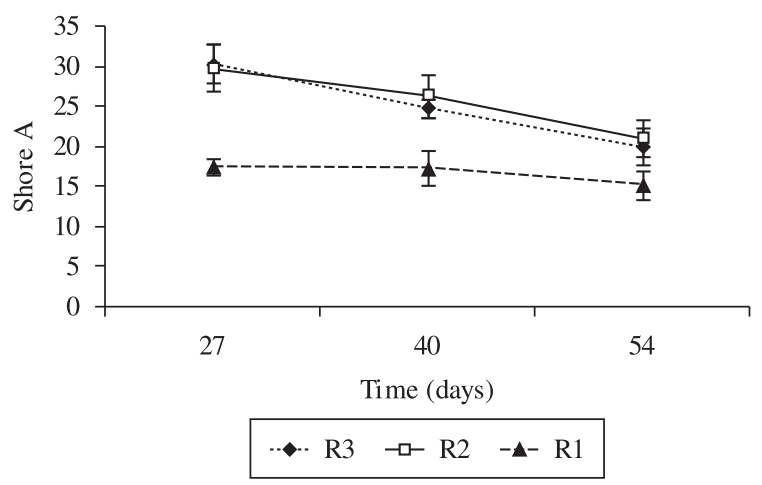

Figure 8. Shore A hardness as a function of time in propellant regions R1, $\mathrm{R} 2$ and $\mathrm{R} 3$ aged at $80^{\circ} \mathrm{C}$.

throughout the sample submitted to the higher temperature aging. This is probably caused by the polymeric matrix, which is responsible for the mechanical properties of the propellant, that is already formed and has the usual trend of hardening by loss of plasticizer and oxidation ${ }^{[2,14-15]}$.

Otherwise, the higher temperature aging produced changes in the interaction between the polymer and solid particles, as show previously by SEM analyses (Figure 6). In addition, moisture can also disturb this interaction and can cause a reduction in hardness of the propellant. 


\section{Conclusions}

A mathematical model of Fick's second law of diffusion applied in this work allowed to calculate the diffusion coefficients of the DOZ plasticizer with success. The agreement between the simulated and experimental values validated this model. Based on the concentration gradient data it is possible to conclude that the diffusion process began in the early stages of curing.

The results of the hardness tests carried out with samples aged at room temperature and $80{ }^{\circ} \mathrm{C}$ showed a softening of the propellant in the layer located at $3 \mathrm{~mm}$ from the interface of the liner and rubber. However, during aging a trend of increasing the hardness was observed for the samples aged at room temperature while for the samples aged at $80{ }^{\circ} \mathrm{C}$ the opposite behavior was verified. Both changes can cause damage, mainly in the interface region and affect the performance and security of the rocket motor.

The SEM analysis showed changes in the propellant surface during the aging period. The softening of the propellant registered by the hardness tests at $80{ }^{\circ} \mathrm{C}$ is consistent with the surface observed by the SEM images as well as the hardening at room temperature.

\section{Acknowledgments}

The authors are grateful to the Brazilian agency CNPq for its financial support and to the Divisão de Química do Instituto de Aeronáutica e Espaço (AQI/IAE).

\section{References}

1. Rezende, L. C. - "Envelhecimento de propelente compósito à base de polibutadieno hidroxilado", Tese Doutorado, Universidade Estadual de Campinas, Brasil (2001).

2. Sutton, G. P. - "Rocket Propulsion elements", John Wiley and Sons, New York (1986).

3. Lourenço, V. L. et al - Polímeros, 16, p.66 (2006).

4. Haska, S. B.; Bayramli, E.; Pekel, F. \& Özkar, S. - J. Appl. Polym. Sci., 64, p.2347 (1998)
5. Bandgar, B. M.; Krishnamurthy, T.; Mukundan, T. \& Sharma, K. C. - J. Appl. Polym. Sci., 85, p.1002 (2002).

6. Saleem, M.; Asfour, A. A. \& De Kee, D. - J. Appl. Polym. Sci., 37, p.617 (1989)

7. Sciamareli, J.; Takahashi, M. F. K.; Teixeira, J. M. \& Iha, K. - Quim. Nova, 25, p.107 (2002).

8. Dilsiz, N. \& Ünver, A. - J. Polym. Sci., 101, p.2538 (2006).

9. Byrd, J. D. \& Guy, C. A. in: AIAA/SAE/ASME/ASEE 21st Joint Propulsion Conference, Monterey, California, p.1438 (1985).

10. Pröbster, M. \& Schmucker, R. M. - Bal. Act. Astr., 13, p.599 (1986).

11. Gottlieb, L. \& Bar, S. - Prop Expl. Pyr., 28, p.12 (2003).

12. Cristiansen, A. G.; Layton, L. H. \& Carpenter, R. L. - J. Spacraf., 18, p.211 (1981).

13. Nagle, D. J.; Celina, M.; Rintoul, L. \& Fredericks, P. M. - Pol. Deg. Stab., 92, p.1446 (2007).

14. Celina, M.; Graham, A. C.; Gillen, K. T.; Assink, R. A. \& Minier, L. M. - Rub. Chem. Tech., 73, p.779 (2000).

15. Judge, M. D. - Prop. Expl. Pyr., 8, p.114 (2003).

16. Hocauğlu, Ö.; Özelbege, T.; Pekel, F. \& Özkar, S. - J. Appl. Polym. Sci., 79, p.959 (2001).

17. Davenas, A. - "Solid rocket propulsion technology", Pergamon Press, New York (1979).

18. Libardi, J. - "Estudo do fenômeno de difusão de plastificantes em propelente compósito sólido à base de polibutadieno hidroxilado utilizado em motores foguete", Tese doutorado, Universidade Estadual de Campinas, Brasil (2009).

19. Crank, J. - "Mathematics in Diffusion", Claredon, Oxford (1957).

20. American Society For Testing and Materials. - "ASTM D 2240 - 05: Standard Test Method for Rubber Property: Durometer Hardness" (2005).

Enviado: 04/07/09

Reenviado: 05/04/10

Aceito: $16 / 04 / 10$

DOI: $10.1590 / \mathrm{S} 0104-14282010005000048$ 